\title{
Inferior epigastric artery pseudoaneurysm following abdominal paracentesis in a patient with chronic kidney failure: a case report and review of literature
}

\author{
Behnam Kian ${ }^{1}$ and Arash Teimouri ${ }^{1}$ \\ ${ }^{1}$ Shiraz University of Medical Sciences
}

November 14, 2021

\begin{abstract}
Inferior epigastric artery pseudoaneurysm is a rare complication following abdominal wall procedures near the artery. This is a case of Inferior epigastric artery pseudoaneurysm after therapeutic paracentesis for large volume ascites caused by chronic kidney failure. The patient was operated on, and the artery was ligated.
\end{abstract}

\section{Hosted file}

case report.EIA (1).docx available at https://authorea.com/users/445986/articles/545341inferior-epigastric-artery-pseudoaneurysm-following-abdominal-paracentesis-in-a-patientwith-chronic-kidney-failure-a-case-report-and-review-of-literature

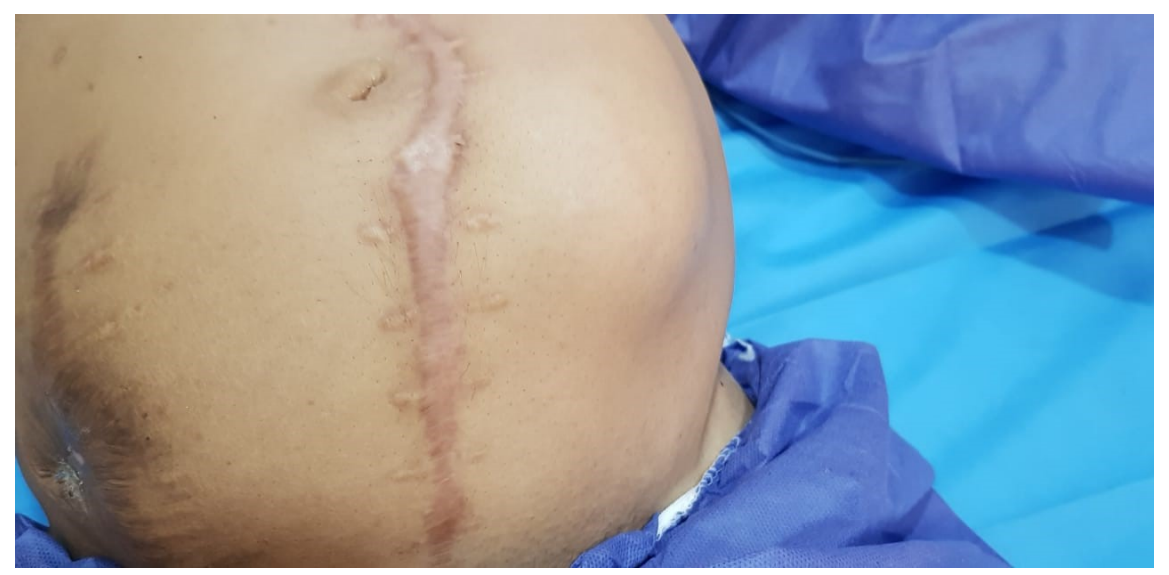




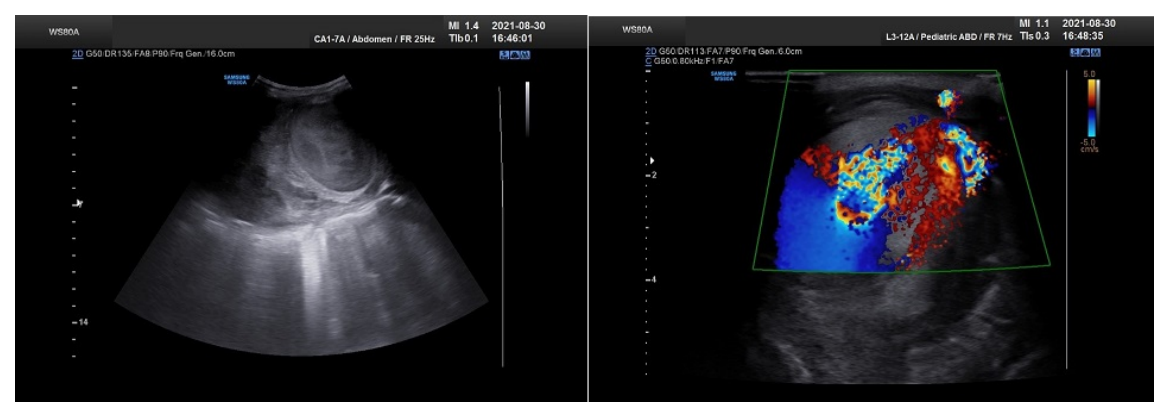




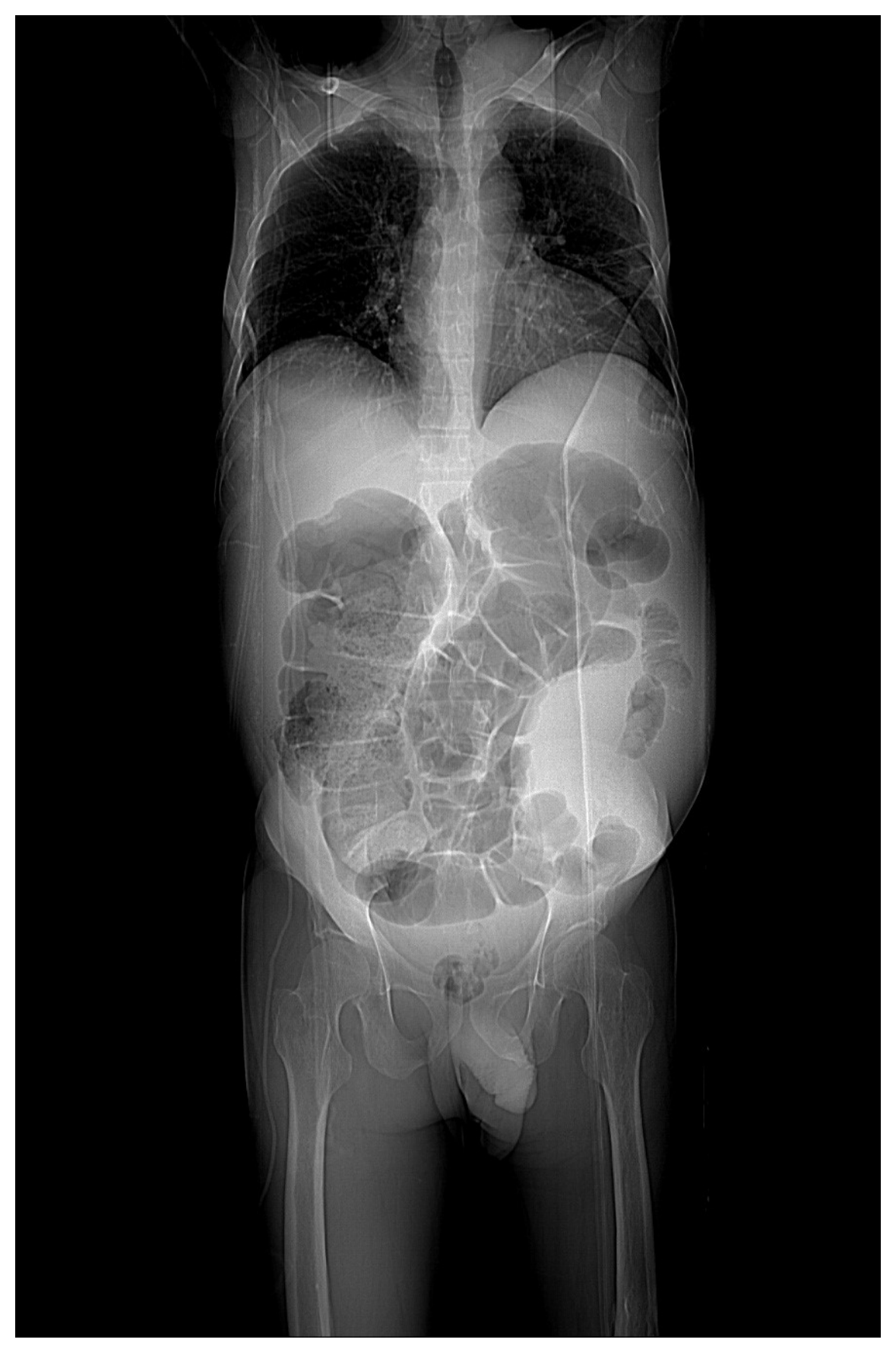




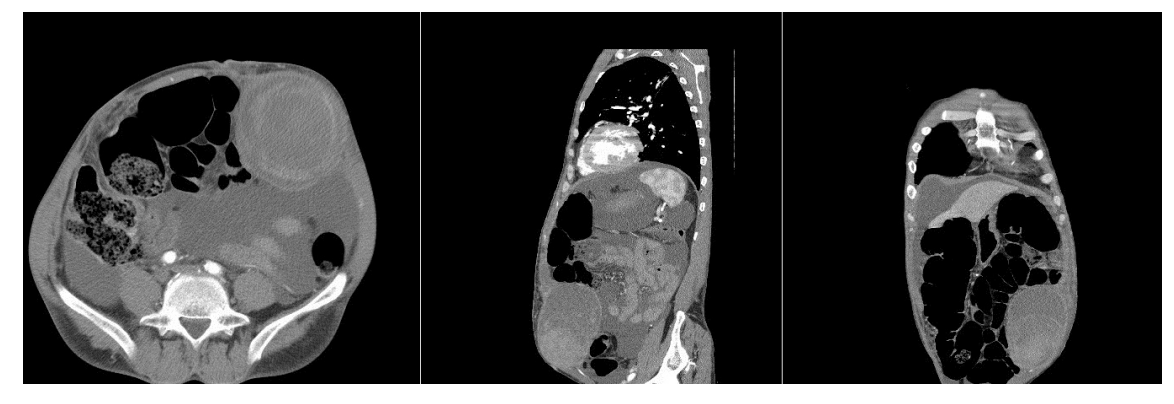

